Al Maqayis : Jurnal Pendidikan Bahasa Arab dan Kebahasaaraban

doi: https://dx.doi.org/10.18592/jams.v6i2.5217

Kerjasama S2 Pendidikan Bahasa Arab dengan IMLA Kal-Sel

\title{
ANALISIS BUKU AJAR BAHASA ARAB MI KELAS IV KURIKULUM 2013 TERBITAN KEMENAG RI TAHUN 2020
}

\author{
Dehendar Ulil Albab \\ Pendidikan Bahasa Arab Pascasarjana UIN Antasari Banjarmasin \\ CorrespondingE-mail: dehendar123@uin-antasariac.id
}

\begin{abstract}
Textbooks are an important component in learning, therefore they must meet the criteria for textbooks that are suitable for use in accordance with applicable regulations. And the material contained in the book is material that has a good quality level. The purpose of this study is to determine the quality level of Arabic language books for class IV published by the Ministry of Religion of the Republic of Indonesia in 2020. The method used is library research and content analysis. Based on the results of the analysis, it can be seen if there are still some errors in terms of content, presentation, language, and graphics. And further research is needed regarding this book in the future.
\end{abstract}

Keywords: $\quad$ Textbooks, Arabic Language, Analaysis

\section{Pendahuluan}

Seiring perubahan zaman, kehidupan dan kebiasaan masyarakat di Indonesia sekarang sudah mengalami beberapa perubahan karena datangnya pengaruh media digital, pengetahuan, serta ilmu-ilmu lain. ${ }^{1}$ Dengan selalu berkembangnya zaman, maka akan muncul pula masalah-masalah serta tantangan yang akan dihadapi.

Kurangnya kemampuan masyarakat dalam hal literasi menjadi salah satu masalah yang muncul sebab dari berkembangnya zaman, teknologi, serta sistem pendidikan yang kurang sesuai. ${ }^{2}$ Oleh karena itu, dengan adanya pendidikan di berbagai jenjang diharapkan agar mampu menghasilkan individu-individu yang memiliki kemampuan baik secara pengetahuan, keterampilan, dan sikap.

\footnotetext{
${ }^{1}$ Muhammad Syaifullah and Nailul Izzah, "Kajian Teoritis Pengembangan Bahan Ajar Bahasa Arab," Arabiyatuna : Jurnal Bahasa Arab Vol. 3, no. 1 (2019): h. 128.

2 Sutri Ramah and Miftahur Rohman, "Analisis Buku Ajar Bahasa Arab Madrasah Aliyah Kurikulum 2013," Arabiyatuna: Jurnal Bahasa Arab Vol. 2, no. 2 (2018): h. 142.
} 
Al Ma qa yis Jurnal Pendidikan Bahasa Arab dan Kebahasaaraban, 5 (2), 2018 p- ISSB 23381337 e-ISSN 2615-3890

Dalam pelaksanaannya, sebuah pendidikan memerlukan namanya pedoman agar apa yang direncanakan dapat tercapai dengan baik. Dan salah satunya yaitu dengan adanya kurikulum yang sudah mengalami beberapa perubahan-perubahan karena perkembangan zaman.

Di Indonesia sekarang diterapkan Kurikulum 2013 yang mana merupakan kurikulum yang diharapkan mampu memperkuat sistem pembelajaran dan penilaian yang berbasis kompetensi guna mencapai kompetensi sikap, pengetahuan, dan keterampilan pada setiap anak didik. Di dalamnya terdapat pula pendekatan saintifik yang menjadi ciri khas kurikulum ini yang bertujuan agar mampu mendorong siswa supaya lebih cakap dalam hal mengamati, mengumpulkan data, bertanya, mencoba, menalar, dan mengkomunikasikan hasil pengamatan mereka. ${ }^{3}$

Membentuk insan yang produktif, kreatif, inovatif, dan efektif melalui adanya keterampilan, penguatan sikap, dan pengetahuan adalah salah satu dari tujuan diberlakukannya Kurikulum 2013. Karena pada masa sekarang pergerakan atau perkembangan pendidikan sudah sangat berbeda dengan apa yang dilaksanakan pada masa-masa sebelumnya. Pada masa sekarang sudah banyak berkembang teknologiteknologi, baik komunikasi, informasi, dan komputasi. ${ }^{4}$

Sudah menjadi suatu hal yang sangat penting dalam hal meningkatkan kualitas pendidikan. Oleh karenanya dalam hal itu, pemerintah berupaya untuk menyediakan sumber-sumber pendidikan seperti buku ajar kepada tiap sekolah.

Menurut Munir, bahwa sumber belajar adalah bahan-bahan yang dimanfaatkan dan diperlukan untuk membantu guru maupun siswa dalam proses pembelajaran. ${ }^{5}$ Definisi lain sumber belajar (learning resources) adalah semua sumber baik berupa data, orang maupun wujud tertentu yang dapat digunakan oleh peserta didik dalam belajar, baik secara terpisah maupun secara terkombinasi sehingga mempermudah peserta didik dalam mencapai tujuan belajar atau kompetensi tertentu. ${ }^{6}$

Oleh sebab itu pengadaan sumber belajar pada setiap sekolah merupakan hal yang sangat penting. Tanpa adanya sumber belajar, guru akan kesulitan untuk mendapatkan materi-materi yang akan disampaikan kepada peserta didik. Dalam hal ini sumber belajar

${ }^{3}$ Laila Faoziyah and Nailul Izzah, "Analysis of Arabic Language Textbooks for Madrasah Aliyah Class XI Based on the 2013 Curriculum | Analisis Buku Ajar Bahasa Arab Madrasah Aliyah Kelas XI Berdasarkan Kurikulum 2013," Mantiqu Tayr: Journal of Arabic Language Vol. 1, no. 2 (July 2021): h. 119.

${ }^{4}$ Abdul Majid, Pendekatan IImiah Dalam Implemenasi Kurikulum 2013 (Bandung: PT Remaja Rosdakarya, 2014), h. 1-2.

${ }^{5}$ Rini Dwi Susanti, "STUDI ANALISIS MATERI AJAR "BUKU TEKS PELAJARAN" PADA MATA PELAJARAN BAHASA ARAB DI KELAS TINGGI MADRASAH IBTIDAIYAH," Arabia Vol. 5, no. 2 (July 2013): h. 200.

${ }^{6}$ Mabrurrosi, "Analisis Buku Ajar Bahasa Arab Karya Dr. D. Hidayat," Al-Irfan Vol. 3, no. 2 (2020): h. 238. 
Al Maqayis Jurnal Pendidikan Bahasa Arab dan Kebahasaaraban, 5 (2), 2018 p-ISSN 2338-1337 e-ISSN 2615-3890

bisa berupa alat-alat media cetak seperti buku, koran, dan majalah. Selain itu manusia itu sendiri dan lingkungan mereka juga bisa menjadi sumber belajar bagi siswa dan guru.

Buku adalah salah satu sumber belajar yang digunakan oleh para siswa dan guru dalam membantu kegiatan pembelajaran di kelas. ${ }^{7}$ Namun buku itu sendiri memiliki hal-hal yang harus diperhatikan agar buku tersebut mudah dipahami dan segala tujuan yang telah direncanakan dapat terlaksana. Hal-hal tersebut salah satunya dilihat dari segi isi dan tampilan yang terdapat pada buku tersebut.

Keberadaan buku yang sedemikian rupa dapat memberikan pengaruh yang besar dalam proses pembelajaran siswa di kelas bersama guru. Sebab dengan banyaknya bukubuku yang beredar bisa menjadi salah satu cara untuk menilai terkait kemajuan dan kemunduran suatu pendidikan. ${ }^{8}$

Dalam pembelajaran, buku menjadi salah satu sumber belajar yang paling utama dan paling umum digunakan pada setiap jenjang mulai dari SD sampai Perguruan Tinggi. Pada bagian ini penulis fokus kepada buku ajar bahasa Arab tingkat Madrasah Ibtidaiyah kelas IV yang diterbitkan oleh Kemenag RI tahun 2020. Tetapi terkadang buku yang diharapkan dapat membantu para guru justru masih terdapat beberapa kesalahankesalahan. Sebab mulai dari awal kurikulum 2013 ditetapkan sampai sekarang, buku tersebut harus melewati beberapa revisi-revisi terkait isi dan lain-lain.

Pada dasarnya, buku-buku yang tersedia dan diterbitkan oleh Kemenag RI adalah "dokumen hidup". Dikatakan seperti itu karena, buku tersebut akan selalu dilakukan perbaikan, pembaruan, dan pemutakhiran terkait dengan isi dari buku agar sesuai dengan perkembangan zaman. Jadi buku yang ada ini tidak semata-mata dianggap sudah sempurna tanpa memiliki kesalahan-kesalahan. Dan munculnya buku ini bisa dibilang sangat cepat dan tergesa-gesa karena pelaksanaan kurikulum 2013 yang terus berubah mengikuti zaman. Alhasil, memunculkan banyak kesalahan-kesalahan yang ditemukan dan mengharuskan dilakukannya analisis dan perbaika leibh lanjut oleh para pelaksanan pendidikan.

Dalam buku ini terdapat 6 tema pembahasan meliputi

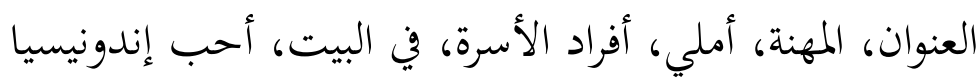

Selain itu, pada kesemua tema juga disajikan terkait 4 kemampuan berbahasa meliputi, menyimak, berbicara, menulis, dan membaca. Setiap tema pembahasan juga dilengkapi

7 Martatik, "ANALISIS BUKU BAHASA ARAB PENDEKATAN SAINTIFIK KURIKULUM 2013 MADRASAH IBTIDAIYAH KELAS I," Andagogi Jurnal Diklat Teknis Vol. 6, no. 1 (June 2018): h. 105.

8 Nurul Hadi, "ANALISIS CONTENT BUKU AJAR BAHASA ARAB (PENDEKATAN SAINTIFIK KURIKULUM 2013) KELAS I MADRASAH IBTIDAIYAH TERBITAN KEMENTRIAN AGAMA REPUBLIK INDONESIA 2014," IJAZ ARABI Journal of Arabic Learning Vol. 1, no. 1 (April 2018): h. 37.

9 Martatik, "ANALISIS BUKU BAHASA ARAB PENDEKATAN SAINTIFIK KURIKULUM 2013 MADRASAH IBTIDAIYAH KELAS I," h. 105. 
Al Maqayis Jurnal Pendidikan Bahasa Arab dan Kebahasaaraban, 5 (2), 2018

p- ISSB 23381337 e-ISSN 2615-3890

kosakata juga tarkib atau qawaid dan pada kosakata juga ditampilkan gambar yang bisa menunjukkan maksud dari kosakata yang dimaksud.

Pembuatan artikel ini ditujukan untuk melakukan analisis terhadap buku Bahasa Arab MI pada kelas 4 terbitan Kemenag RI tahun 2020 dan melihat kesesuaian isi buku dengan kurikulum yang berlaku. Sebab setelah dilihat dengan baik Buku Bahasa Arab MI kelas IV yang diterbitkan oleh Kemenag RI berkurikulum 2013 yang merupakan cetakan tahun 2020 dirasa juga perlu dilakukan beberapa analisis terkait isi buku tersebut. Sebab berdasarkan apa yang didapat penulis terdapat beberapa materi yang dihilangkan jika dibandingan dengan buku Bahasa Arab cetakan tahun 2014 dan Permenag RI no 912. Lalu ada materi baru yang ditambahkan ke dalam buku Bahasa Arab MI kelas IV cetakan 2020. Selain itu ada ketidakjelasan gambar terkait kosakata pada buku.

1. Kurikulum Bahasa Arab MI kelas IV

Dalam kurikulum Bahasa Arab MI memiliki ruang lingkup tema-tema yang dibahas yaitu tentang perkenalan, peralatan madrasah, pekerjaan, alamat, keluarga, anggota badan, di rumah, di kebun, di madrasah, di laboratorium, di perpustakaan, di kantin, jam, kegiatan sehari-hari, pekerjaan, rumah, dan rekreasi. ${ }^{10}$

Berdasarkan permenag RI No 912 tahun 2013 dapat diketahui materi-materi yang diajarkan dalam pembelajaran Bahasa Arab tingkat MI adalah sebagai berikut: ${ }^{11}$

a. Pada semester ganjil akan membahasa materi tentang:

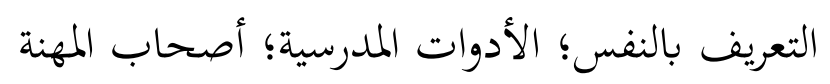

Tarkib:

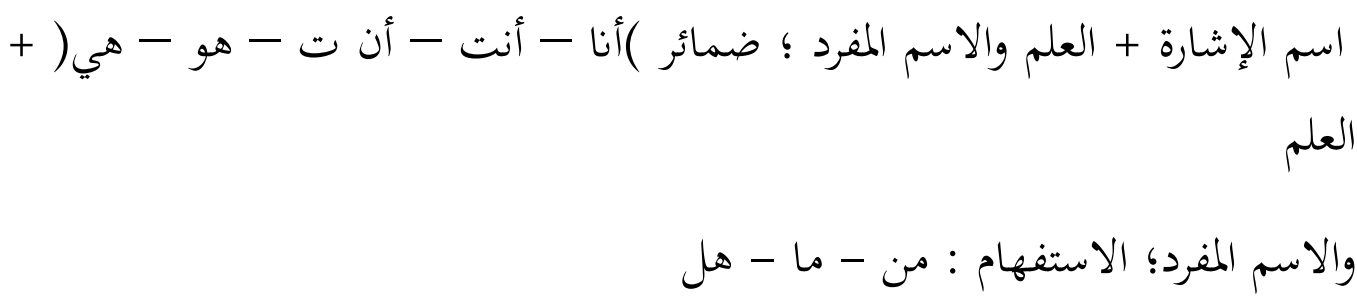

b. Pada semester genap akan membahas materi tentang:

$$
\text { العنوان؛ أفراد الأسرة؛ الأسرة في البيت }
$$

10 Permenag RI, Nomor 912 Tahun 2013 Tentang KURIKULUM MADRASAH 2013 MATA PELAJARAN PENDIDIKAN AGAMA ISLAM DAN BAHASA ARAB, 2013, h. 42.

${ }^{11}$ Ibid., h. 107-109. 
Al Maqayis Jurnal Pendidikan Bahasa Arab dan Kebahasaaraban, 5 (2), 2018 p-ISSN 2338-1337 e-ISSN 2615-3890

Tarkib:

$$
\text { الأرقام } 11 \text { والضمائر - } 1 \text { المتصلة المفردة ؛ الاستفهام : أين ؟ والجار : في }
$$

2. Pengertian dan Fungsi Buku Ajar

Buku adalah suatu komponen penting dalam pembelajaran yang didalamnya terdapat materi-materi berupa teks atau ilustrasi gambar yang menjadi sumber untuk guru dan siswa dalam mempelajari suatu pelajaran dan mencapai tujuan yang direncanakan. ${ }^{12}$ Yang mana materi di dalam buku telah tersusun secara sistematis sehingga memudahkan siswa memahami materi secara utuh dan terpadu. ${ }^{13}$

Seperti yang tercantum pada Peraturan Menteri Pendidikan dan Kebudayaan Republik Indonesia Nomor 8 Tahun 2016 Pasal 1 yaitu: "Buku ajar pelajaran adalah sumber pembelajaran utama untuk mencapai kompetensi dasar dan kompetensi inti dan dinyatakan layak oleh kementerian Pendidikan dan Kebudayaan untuk digunakan pada satuan pendidikan." ${ }^{14}$

Selain itu terdapat juga ciri-ciri khusus pada buku ajar seperti yang dikemukakan oleh Muslich yaitu sebagai berikut: 1) disusun sesuai kurikulum yang berlaku, 2) tujuan tertentu menjadi fokus utama, 3) terdapat sajian tentang satu pelajaran tertentu, 4) kegiatan belajar siswa menjadi orientasi utama, 5) dapat dijadikan guru sebagai pedoman dalam kegiatan pembelajaran, 6) penyajian buku sesuai dengan tingkat kemampuan siswa. ${ }^{15}$ Dari bagian di atas dapat diketahui jika buku adalah salah satu komponen penting dalam pembelajaran yang didalamnya tertuang materi-materi dan memiliki ciri-ciri khusus yang tidak dimiliki oleh bukubuku lainnya.

Adapun menurut Lange buku teks adalah buku standar suatu bidang tertentu yang terdiri dari buku utama dan tambahan. Sedangkan menurut Buckingham buku teks adalah segala sesuatu yang digunakan pada setiap jenjang pendidikan guna mendukung berjalannya suatu kegiatan pembelajaran. ${ }^{16}$

${ }^{12}$ Muh. Sabilar Rosyad, "Analisis Buku Ajar Bahasa Arab Siswa Kelas VIII MTs/SMP Islam Dalam Perspektif Gender," JALIE: Journal of Applied Linguistics and Islamic Education Vol. 2, no. 2 (September 2018): h. 380.

${ }^{13}$ Afifa Wijdan Azhari, "ANALISIS BUKU AJAR BAHASA ARAB KELAS VI MADRASAH IBTIDAIAH TERBITAN KARYA TOHA PUTRA," Alsuniyat: Jurnal Penelitian Bahasa, Sastra, dan Budaya Arab Vol. 1, no. 2 (Oktober 2018): h. 125.

${ }^{14}$ Peraturan Mentri Pendidikan dan Kebudayaan, Nomor 8 Tahun 2016 Tentang Buku Yang Digunakan Oleh Satuan Pendidikan, 2015, h. 2.

${ }^{15}$ M. Musclich, Text Book Writing : Dasar-Dasar Pemahaman, Penulisan, Dan Pemakaian Buku Teks (Sleman: AR-RUZZ Media, 2010), h. 61.

16 Susanti, "STUDI ANALISIS MATERI AJAR "BUKU TEKS PELAJARAN" PADA MATA PELAJARAN BAHASA ARAB DI KELAS TINGGI MADRASAH IBTIDAIYAH," h. 207. 
Al Ma qayis Jurnal Pendidikan Bahasa Arab dan Kebahasaaraban, 5 (2), 2018

p- ISSB 23381337 e-ISSN 2615-3890

Sitepu juga berpendapat bahwa buku ajar berfungsi sebagai panduan bagi guru serta siswa dalam kegiatan belajar mengajar pada bidang tertentu. ${ }^{17}$ Jadi dapat dilihat bahwa buku ajar mempunyai fungsi sebagai pedoman dalam kegiatan pembelajaran setiap bidang studi yang ada di setiap jenjang pendidikan.

Adapun urgensi buku ajar sebagimana yang paparkan oleh Al-Gali dan Abdullah adalah memunculkan komunikasi antara guru dan siswa serta menciptakan sebuah kegiatan pembelajaran sehingga dapat mencapai tujuan yang diinginkan. ${ }^{18}$ Dengan demikian, diperlukan adanya buku ajar bahasa Arab yang berkualitas agar dapat memenuhi kebutuhan tersebut.

Berdasarkan beberapa pendapat mengenai buku teks di atas, maka dapat disimpulkan bahwa adanya buku ajar yang memiliki tingkat mutu yang bagus sangatlah diperlukan guna memenuhi kebutuhan dalam suatu pembelajaran. Yang mana buku ajar sendiri adalah buku yang digunakan di setiap bidang studi tertentu yang bisa menjadi buku utama atau tambahan dalam pembelajaran yang merupakan hasil dari para pakar-pakar bidang tertentu. Yang didalamnya juga dilengkapi akan hal-hal yang bisa membantu proses pembelajaran sehingga para pemakai buku tersebut dapat memahami dengan mudah dan runtut.

3. Kriteria Isi Bahan Ajar

Sebuah buku ajar akan layak digunakan jika memiliki kritera-kriteria yang telah ditentukan oleh satuan pendidikan. Seperti yang telah ditetapkan oleh BSNP bahwasannya isi dalam buku ajar harus memenuhi dari aspek materi, aspek kebahasaan, aspek penyajian materi, dan aspek kegrafikaan. ${ }^{19}$

Disini Muslich kembali menjelaskan terkait aspek-aspek yang telah ditetapkan oleh BSNP, yaitu: ${ }^{20}$

Aspek kelayakan isi terdapat tiga indikator yang harus diperhatikan, yaitu: kesesuaian uraian materi dengan SK dan KD yang terdapat dalam kurikulum keakuratan materi, dan materi pendukung pembelajaran.

Aspek kelayakan penyajian terdapat tiga indikator yang harus diperhatikan, yaitu: teknik penyajian, penyajian pembelajaran, dan kelengkapan penyajian.

Aspek kelayakan bahasa terdapat tiga indikator yang harus diperhatikan, yaitu: kesesuaian pemakaian bahasa dengan tingkat perkembangan siswa, pemakaian

${ }^{17}$ Sitepu, Penulisan Buku Teks Pelajaran (Bandung: PT Remaja Rosdakarya, 2015), h. 21.

${ }^{18}$ A. Al-Gali and Abdul Hamid Abdullah, Menyusun Buku Ajaran Bahasa Arab (Padang: Akademia, 2012), h. 10.

${ }^{19}$ Peraturan Mentri Pendidikan dan Kebudayaan, Nomor 8 Tahun 2016 Tentang Buku Yang Digunakan Oleh Satuan Pendidikan, h. 5.

${ }^{20}$ Musclich, Text Book Writing : Dasar-Dasar Pemahaman, Penulisan, Dan Pemakaian Buku Teks, h. 293-303. 
Al Maqayis Jurnal Pendidikan Bahasa Arab dan Kebahasaaraban, 5 (2), 2018 p-ISSN 2338-1337 e-ISSN 2615-3890

bahasa yang komunikatif, dan pemakaian bahasa memenuhi syarat ketentuan dan keterpaduan alur berpikir.

Sedangkan dari aspek kelayakan kegrafikaan, ada tiga indikator yang harus diperhatikan, yaitu: ukuran buku, desain kulit buku, dan desain isi buku.

Materi adalah salah satu hal penting yang harus ada pada suatu buku ajar dan harus disusun secara sistematis, runtut, terpadu, dan sesuai dengan kompetensi yang akan dikuasi agar siswa mampu dengan mudah dalam menguasai kompetensi tersebut secara utuh dan terpadu. Oleh karena itu, adanya buku yang tersusun sesuai dengan kriteria-kriteria yang telah ditentukan akan membuat kegiatan pembelajaran dapat terlaksana dengan baik sehingga tujuan yang tercantum pada kurikulum dapat tercapai.

Disini Al-Qasimy menyebutkan terkhusus buku ajar bahasa Arab terdapat beberapa komponen materi yang harus dipenuhi yaitu: 1) Bacaan-bacaan (almuțāla'ah) tentang hal-hal yang berkaitan dengan kehidupan siswa, 2) Kaidah-kaidah bahasa Arab (qawā’id al-lugah al-'Arabiyyah) dengan menggunakan rumusan bahasa siswa yang bersangkutan, 3) Beberapa latihan (al-tadribat) lisan maupun tertulis yang dikerjakan siswa dengan bimbingan guru; 4) Tahapan-tahapan penyajian bahan ajar harus diperhatikan agar tidak merugikan efektivitas belajar mengajar bahasa, 5) Kamus singkat yaitu kamus yang berisi kata-kata baru dalam buku tersebut yang dirasa sulit oleh siswa, 6) Materi Pendukung yang meliputi perkamusan, buku-buku latihan, dan buku pedoman bagi guru. ${ }^{21}$

Dalam sebuah penelitian menyebutkan bahwa terdapat materi-materi yang sebaiknya diajarkan pada jenjang Madrasah Ibtidaiyah yaitu pengenalan huruf hijaiyah, perkenalan 1 , perkenalan 2 , perkenalan 3 , anggota badan, peralatan sekolah, makanan dan minuman, hari-hari, nama-nama bulan, islam, hobiku, di kebun, profesi, alamat, keluarga, di rumah, benda-benda di sekitar. ${ }^{22}$

Yang artinya dalam pembelajaran bahasa Arab di MI sudah memiiki standar materi-materi yang harus diajarkan sehingga guru tidak salah dalam mengajarkan kepada para peserta didik.

\section{Metodologi Penelitian}

Penelitian ini bertujuan untuk menganalisis isi materi yang ada pada buku bahasa Arab Madrasah Ibtidaiyah kelas IV yang merupakan terbitan Kemenag RI tahun 2020.

\footnotetext{
${ }^{21}$ Afifa Wijdan Azhari, "ANALISIS BUKU AJAR BAHASA ARAB KELAS VI MADRASAH IBTIDAIAH TERBITAN KARYA TOHA PUTRA," h. 106.

${ }^{22}$ Azkia Muharom Albantani, "Pembelajaran Bahasa Arab Di Madrasah Ibtidaiyah: Sebuah Ide Terobosan," Attadib Journal Of Elementary Education Vol. 3, no. 2 (Desember 2018): h. 163.
} 
Al Ma qa yis Jurnal Pendidikan Bahasa Arab dan Kebahasaaraban, 5 (2), 2018 p- ISSB 23381337 e-ISSN 2615-3890

Metode yang digunakan dalam penulisan artikel ini adalah metode library research (studi kepustakaan). Yaitu metode yang pengumpulan datanya didapatkan dari kegiatan membaca dan menganalisis beberapa literatur bisa berupa buku, media cetak, ataupun jurnal-jurnal, dan literature lain yang terkait. Untuk menganalisis data yang sudah di dapat menggunakan content analysis berdasarkan ketentuan yang ditetapkan BSNP yaitu terkait aspek materi, aspek penyajian, aspek kebahasaan, dan aspek kegrafikaan. Sumber data yang digunakan adalah buku bahasa Arab untuk MI kelas IV yang diterbitkan oleh Kemenag RI tahun 2020.

\section{Hasil dan Pembahasan}

\section{Aspek Isi}

\begin{tabular}{|c|c|c|c|}
\hline \multicolumn{4}{|c|}{ BAB I } \\
\hline No. & Halaman & Kesalahan & Perbaikan \\
\hline 1 & $6-7$ & $\begin{array}{l}\text { Peletakkan materi tentang } \\
\text { mufradat beserta latihannya }\end{array}$ & $\begin{array}{l}\text { Seharusnya materi } \\
\text { mufradat diletakkan di } \\
\text { halaman } 6 \text { sebagai } \\
\text { materi pertama yang } \\
\text { diajarkan }\end{array}$ \\
\hline 2 & 6 & $\begin{array}{l}\text { Kurangnya gambar pada bagian } \\
\text { percakapan }\end{array}$ & $\begin{array}{l}\text { Didalam percakapan } \\
\text { seharusnya ditambah } \\
\text { gambar telpon, sebab di } \\
\text { percakapan disebutkan } \\
\text { kata tersebut } \\
\text { sebagaimana rumah }\end{array}$ \\
\hline 3 & $\begin{array}{c}7, \\
8,9,10,11,13\end{array}$ & Baris tertinggal pada kosakata & $\begin{array}{l}\text { Perlu ditambahkan baris } \\
\text { kasrah pada kosakata } \\
\text { شَارع }\end{array}$ \\
\hline 4 & & $\begin{array}{l}\text { Gambar mata pada setiap } \\
\text { perintah }\end{array}$ & $\begin{array}{l}\text { Alangkah baik diganti } \\
\text { dengan gambar yang } \\
\text { lain. Sebab gambar } \\
\text { tersebut terlihat kurang } \\
\text { pas karena warnanya. }\end{array}$ \\
\hline 5 & 9 & Kِفي شَارِع حَسَنِ الدِّيْنِ Kesalahan baris & م فِي شَارِع حَسَنُ الدِيِينِ \\
\hline 6 & 9 & $\begin{array}{l}\text { Tidak ada baris pada soal } \\
\text { nomor } 5\end{array}$ & بَبِيْتِ \\
\hline 7 & 3 & $\begin{array}{l}\text { Ketidaksesuaian urutan } \\
\text { Indikator Pencapaian }\end{array}$ & $\begin{array}{l}\text { Seharusnya indikator } \\
\text { nomor } 2 \text { berada di } \\
\text { nomor } 1\end{array}$ \\
\hline
\end{tabular}


Al Maqayis Jurnal Pendidikan Bahasa Arab dan Kebahasaaraban, 5 (2), 2018 p-ISSN 2338-1337 e-ISSN 2615-3890

\begin{tabular}{|c|l|l|l|}
\hline 8 & 4 & $\begin{array}{l}\text { Ketidaksesuaian isi Indikator, } \\
\text { KD dengan Peta Konsep }\end{array}$ & $\begin{array}{l}\text { Seharusnya di Peta } \\
\text { konsep juga dituliskan } \\
\text { tentang Qawaid }\end{array}$ \\
\hline
\end{tabular}

\begin{tabular}{|c|c|c|c|}
\hline \multicolumn{4}{|c|}{ BAB II } \\
\hline No. & Halaman & Kesalahan & Perbaikan \\
\hline 1 & $19-20$ & $\begin{array}{l}\text { Peletakkan materi tentang } \\
\text { mufradat beserta latihannya }\end{array}$ & $\begin{array}{l}\text { Seharusnya materi } \\
\text { mufradat diletakkan di } \\
\text { halaman } 19 \text { sebagai } \\
\text { materi pertama yang } \\
\text { diajarkan }\end{array}$ \\
\hline 2 & & $\begin{array}{l}\text { Gambar mata pada setiap } \\
\text { perintah }\end{array}$ & $\begin{array}{l}\text { Alangkah baik diganti } \\
\text { dengan gambar yang } \\
\text { lain. Sebab gambar } \\
\text { tersebut terlihat kurang } \\
\text { pas karena warnanya. }\end{array}$ \\
\hline 3 & $\begin{array}{c}20,21 \\
22,23,26\end{array}$ & Gambar kosakata kurang sesuai & $\begin{array}{l}\text { - Gambar untuk kosakata } \\
\text { مدرس sebaiknya diganti } \\
\text { dengan gambar seperti } \\
\text { halaman } 19 \text { atau } 23 \\
\text { - Kosakata yang } \\
\text { berwarna hitam puth } \\
\text { alangkah baiknya diganti } \\
\text { dengan yang berwarna } \\
\text { seperti yang lain }\end{array}$ \\
\hline 4 & 24 & 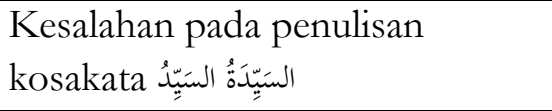 & السَِّّدَدة السمَِّّدُ \\
\hline 5 & 2627 & $\begin{array}{l}\text { Soal latihan bagian Jim terdapat } \\
\text { kosakata yang tidak ada pada } \\
\text { bagian pengenalan mufradat }\end{array}$ & $\begin{array}{l}\text { Pemilihan kosakata } \\
\text { seharusnya disesuaikan } \\
\text { dengan materi mufradat } \\
\text { sebelumnya }\end{array}$ \\
\hline 6 & & $\begin{array}{l}\text { Materi tentang Qawaid tidak ada } \\
\text { bagian khusus langsung contoh } \\
\text { pemakaian }\end{array}$ & $\begin{array}{l}\text { Seharusnya setiap bab } \\
\text { diberikan tempat khusus } \\
\text { untuk materi Qawaid } \\
\text { terkait penjelasan }\end{array}$ \\
\hline 7. & 16 & $\begin{array}{l}\text { Ketidaksesuaian urutan Indikator } \\
\text { Pencapaian }\end{array}$ & $\begin{array}{l}\text { Seharusnya indikator } \\
\text { nomor } 2 \text { berada di } \\
\text { nomor } 1\end{array}$ \\
\hline 8 & 17 & $\begin{array}{l}\text { Ketidaksesuaian isi Indikator, } \\
\text { KD dengan Peta Konsep }\end{array}$ & $\begin{array}{l}\text { Seharusnya di Peta } \\
\text { konsep juga dituliskan } \\
\text { tentang Qawaid }\end{array}$ \\
\hline
\end{tabular}


Al Ma qayis Jurnal Pendidikan Bahasa Arab dan Kebahasaaraban, 5 (2), 2018 p- ISSB 23381337 e-ISSN 2615-3890

\begin{tabular}{|c|c|l|l|}
\hline \multicolumn{3}{|c|}{ BAB III } \\
\hline No. & Halaman & \multicolumn{1}{|c|}{ Kesalahan } & \multicolumn{1}{c|}{ Perbaikan } \\
\hline 1 & 34 & $\begin{array}{l}\text { Peletakkan materi tentang } \\
\text { mufradat beserta latihannya }\end{array}$ & $\begin{array}{l}\text { Seharusnya materi } \\
\text { mufradat diletakkan di } \\
\text { halaman 34 sebagai } \\
\text { materi pertama yang } \\
\text { diajarkan }\end{array}$ \\
\hline 2 & & $\begin{array}{l}\text { Gambar mata pada setiap } \\
\text { perintah }\end{array}$ & $\begin{array}{l}\text { Alangkah baik diganti } \\
\text { dengan gambar yang lain. } \\
\text { Sebab gambar tersebut } \\
\text { terlihat kurang pas } \\
\text { karena warnanya. }\end{array}$ \\
\hline 3 & 39 & $\begin{array}{l}\text { Pemilihan kosakata tidak ada } \\
\text { pada materi mufradat }\end{array}$ & $\begin{array}{l}\text { Seharusnya pemilihan } \\
\text { kosakata pada } \\
\text { disesuaikan dengan } \\
\text { mufradat yang } \\
\text { diperkenalkan }\end{array}$ \\
\hline 4 & & $\begin{array}{l}\text { Materi tentang Qawaid tidak ada } \\
\text { bagian khusus langsung contoh } \\
\text { pemakaian }\end{array}$ & $\begin{array}{l}\text { Seharusnya setiap bab } \\
\text { diberikan tempat khusus } \\
\text { untuk materi Qawaid } \\
\text { terkait penjelasan }\end{array}$ \\
\hline 5 & 31 & $\begin{array}{l}\text { Ketidaksesuaian urutan Indikator } \\
\text { Pencapaian }\end{array}$ & $\begin{array}{l}\text { Seharusnya indikator } \\
\text { nomor 2 berada di } \\
\text { nomor 1 }\end{array}$ \\
\hline 6 & 32 & $\begin{array}{l}\text { Ketidaksesuaian isi Indikator, } \\
\text { KD dengan Peta Konsep }\end{array}$ & $\begin{array}{l}\text { Seharusnya di Peta } \\
\text { konsep juga dituliskan } \\
\text { tentang Qawaid }\end{array}$ \\
\hline
\end{tabular}

\begin{tabular}{|c|c|l|l|}
\hline \multicolumn{2}{|c|}{ BAB IV } \\
\hline No. & Halaman & \multicolumn{1}{|c|}{ Kesalahan } & \multicolumn{1}{|c|}{ Perbaikan } \\
\hline 1 & 52 & $\begin{array}{l}\text { Peletakkan materi tentang } \\
\text { mufradat beserta latihannya }\end{array}$ & $\begin{array}{l}\text { Seharusnya materi } \\
\text { mufradat diletakkan di } \\
\text { halaman 52 sebagai } \\
\text { materi pertama yang } \\
\text { diajarkan }\end{array}$ \\
\hline 2 & & $\begin{array}{l}\text { Gambar mata pada setiap } \\
\text { perintah }\end{array}$ & $\begin{array}{l}\text { Alangkah baik diganti } \\
\text { dengan gambar yang } \\
\text { lain. Sebab gambar } \\
\text { tersebut terlihat kurang } \\
\text { pas karena warnanya. }\end{array}$ \\
\hline
\end{tabular}


Al Maqayis Jurnal Pendidikan Bahasa Arab dan Kebahasaaraban, 5 (2), 2018 p-ISSN 2338-1337 e-ISSN 2615-3890

\begin{tabular}{|c|c|l|l|}
\hline 3 & & $\begin{array}{l}\text { Materi tentang Qawaid tidak ada } \\
\text { bagian khusus langsung contoh } \\
\text { pemakaian }\end{array}$ & $\begin{array}{l}\text { Seharusnya setiap bab } \\
\text { diberikan tempat khusus } \\
\text { untuk materi Qawaid } \\
\text { terkait penjelasan }\end{array}$ \\
\hline 4 & 49 & $\begin{array}{l}\text { Ketidaksesuaian urutan Indikator } \\
\text { Pencapaian }\end{array}$ & $\begin{array}{l}\text { Seharusnya indikator } \\
\text { nomor 2 berada di } \\
\text { nomor 1 }\end{array}$ \\
\hline 5 & 50 & $\begin{array}{l}\text { Ketidaksesuaian isi Indikator, } \\
\text { KD dengan Peta Konsep }\end{array}$ & $\begin{array}{l}\text { Seharusnya di Peta } \\
\text { konsep juga dituliskan } \\
\text { tentang Qawaid }\end{array}$ \\
\hline 6 & & & \\
\hline
\end{tabular}

\begin{tabular}{|c|c|l|l|}
\hline \multicolumn{3}{|c|}{ BAB V } \\
\hline No. & Halaman & \multicolumn{1}{|c|}{ Kesalahan } & \multicolumn{1}{|c|}{ Perbaikan } \\
\hline 1 & 64 & $\begin{array}{l}\text { Peletakkan materi tentang } \\
\text { mufradat beserta latihannya }\end{array}$ & $\begin{array}{l}\text { Seharusnya materi } \\
\text { mufradat diletakkan di } \\
\text { halaman 64 sebagai } \\
\text { materi pertama yang } \\
\text { diajarkan }\end{array}$ \\
\hline 2 & & $\begin{array}{l}\text { Gambar mata pada setiap } \\
\text { perintah }\end{array}$ & $\begin{array}{l}\text { Alangkah baik diganti } \\
\text { dengan gambar yang lain. } \\
\text { Sebab gambar tersebut } \\
\text { terlihat kurang pas } \\
\text { karena warnanya. }\end{array}$ \\
\hline 3 & 39 & $\begin{array}{l}\text { Pemilihan kosakata tidak ada } \\
\text { pada materi mufradat }\end{array}$ & $\begin{array}{l}\text { Seharusnya pemilihan } \\
\text { kosakata pada } \\
\text { disesuaikan dengan } \\
\text { mufradat yang } \\
\text { diperkenalkan }\end{array}$ \\
\hline 4 & & $\begin{array}{l}\text { Materi tentang Qawaid tidak ada } \\
\text { bagian khusus langsung contoh } \\
\text { pemakaian }\end{array}$ & $\begin{array}{l}\text { Seharusnya setiap bab } \\
\text { diberikan tempat khusus } \\
\text { untuk materi Qawaid } \\
\text { terkait penjelasan }\end{array}$ \\
\hline 5 & 61 & $\begin{array}{l}\text { Ketidaksesuaian urutan Indikator } \\
\text { Pencapaian }\end{array}$ & $\begin{array}{l}\text { Seharusnya indikator } \\
\text { nomor 2 berada di } \\
\text { nomor 1 }\end{array}$ \\
\hline 6 & 62 & $\begin{array}{l}\text { Ketidaksesuaian isi Indikator, } \\
\text { KD dengan Peta Konsep }\end{array}$ & $\begin{array}{l}\text { Seharusnya di Peta } \\
\text { konsep juga dituliskan } \\
\text { tentang Qawaid }\end{array}$ \\
\hline
\end{tabular}

\begin{tabular}{|l|l|l|l|}
\hline \multicolumn{3}{|c|}{ BAB VI } \\
\hline No. & Halaman & Kesalahan & Perbaikan \\
\hline
\end{tabular}


Al Maqayis Jurnal Pendidikan Bahasa Arab dan Kebahasaaraban, 5 (2), 2018 p- ISSB 23381337 e-ISSN 2615-3890

\begin{tabular}{|c|l|l|l|}
\hline 1 & 75 & $\begin{array}{l}\text { Peletakkan materi tentang } \\
\text { mufradat beserta latihannya }\end{array}$ & $\begin{array}{l}\text { Seharusnya materi } \\
\text { mufradat diletakkan di } \\
\text { halaman 75 sebagai } \\
\text { materi pertama yang } \\
\text { diajarkan }\end{array}$ \\
\hline 2 & & $\begin{array}{l}\text { Gambar mata pada setiap } \\
\text { perintah }\end{array}$ & $\begin{array}{l}\text { Alangkah baik diganti } \\
\text { dengan gambar yang lain. } \\
\text { Sebab gambar tersebut } \\
\text { terlihat kurang pas } \\
\text { karena warnanya. }\end{array}$ \\
\hline 3 & 39 & $\begin{array}{l}\text { Pemilihan kosakata tidak ada } \\
\text { pada materi mufradat }\end{array}$ & $\begin{array}{l}\text { Seharusnya pemilihan } \\
\text { kosakata pada } \\
\text { disesuaikan dengan } \\
\text { mufradat yang } \\
\text { diperkenalkan }\end{array}$ \\
\hline 4 & & $\begin{array}{l}\text { Materi tentang Qawaid tidak ada } \\
\text { bagian khusus langsung contoh } \\
\text { pemakaian }\end{array}$ & $\begin{array}{l}\text { Seharusnya setiap bab } \\
\text { diberikan tempat khusus } \\
\text { untuk materi Qawaid } \\
\text { terkait penjelasan }\end{array}$ \\
\hline 5 & 72 & $\begin{array}{l}\text { Ketidaksesuaian urutan Indikator } \\
\text { Pencapaian }\end{array}$ & $\begin{array}{l}\text { Seharusnya indikator } \\
\text { nomor 2 berada di } \\
\text { nomor 1 }\end{array}$ \\
\hline 6 & 73 & $\begin{array}{l}\text { Ketidaksesuaian isi Indikator, } \\
\text { KD dengan Peta Konsep }\end{array}$ & $\begin{array}{l}\text { Seharusnya di Peta } \\
\text { konsep juga dituliskan } \\
\text { tentang Qawaid }\end{array}$ \\
\hline
\end{tabular}

Aspek Kebahasaan

\begin{tabular}{|c|c|l|l|}
\hline No. & Halaman & \multicolumn{1}{|c|}{ Kesalahan } & \multicolumn{1}{c|}{ Perbaikan } \\
\hline 1 & Iii & Kesalahan penulisan Hadit & Seharusnya Hadis \\
\hline 2 & Iii & $\begin{array}{l}\text { Kurangnya tanda koma pada } \\
\text { bagian:puji syukur hanya milik } \\
\text { Allah SWT yang telah } \\
\text { menganugerahkan hidayah, } \\
\text { taufiq dan inayah }\end{array}$ & $\begin{array}{l}\text { puji syukur marilah kita } \\
\text { panjatkan kepada Allah } \\
\text { SWT yang telah } \\
\text { menganugerahkan } \\
\text { hidayah, taufiq, dan } \\
\text { inayah-Nya }\end{array}$ \\
\hline 3 & Iii & $\begin{array}{l}\text { Kurangnya tanda koma pada } \\
\text { bagian: al-Qur'an Hadis, Akidah } \\
\text { Akhlak, Fikih, SKI dan Bahasa } \\
\text { Arab untuk jenjang MI, MTs dan } \\
\text { MA/ }\end{array}$ & $\begin{array}{l}\text { al-Qur'an Hadis, Akidah } \\
\text { Akhlak, Fikih, SKI, dan } \\
\text { Bahasa Arab untuk } \\
\text { jenjang MI, MTs dan } \\
\text { MAK semua peminatan. } \\
\text { MAK } \\
\text { Keperluan untuk MA Peminatan }\end{array}$ \\
& & $\begin{array}{l}\text { MAK semua peminatan. } \\
\text { Keperluan untuk MA }\end{array}$ \\
\hline
\end{tabular}


Al Maqayis Jurnal Pendidikan Bahasa Arab dan Kebahasaaraban, 5 (2), 2018 p-ISSN 2338-1337 e-ISSN 2615-3890

\begin{tabular}{|c|c|c|c|}
\hline & & $\begin{array}{l}\text { Keagamaan diterbitkan buku } \\
\text { Tafsir, Hadis, } \\
\text { Ilmu Tafsir, Ilmu Hadit, Ushul } \\
\text { Fikih, Ilmu Kalam, Akhlak } \\
\text { Tasawuf dan Bahasa Arab }\end{array}$ & $\begin{array}{l}\text { Peminatan Keagamaan } \\
\text { diterbitkan buku Tafsir, } \\
\text { Hadis, } \\
\text { Ilmu Tafsir, Ilmu Hadit, } \\
\text { Ushul Fikih, Ilmu Kalam, } \\
\text { Akhlak Tasawuf, dan } \\
\text { Bahasa Arab }\end{array}$ \\
\hline 4 & Iii & $\begin{array}{l}\text { Perkembangan ilmu } \\
\text { pengetahuan, teknologi dan } \\
\text { komunikasi }\end{array}$ & $\begin{array}{l}\text { Perkembangan ilmu } \\
\text { pengetahuan, teknologi, } \\
\text { dan komunikasi }\end{array}$ \\
\hline 5 & Iii & $\begin{array}{l}\text { Dengan demikian, generasi muda } \\
\text { akan memiliki kepribadian, } \\
\text { berkarakter kuat dan tidak } \\
\text { tercerabut dari akar budaya } \\
\text { bangsa namun } \\
\text { tetap bisa menjadi aktor di } \\
\text { zamannya. }\end{array}$ & $\begin{array}{l}\text { Dengan demikian, } \\
\text { generasi muda } \\
\text { akan memiliki } \\
\text { kepribadian, berkarakter } \\
\text { kuat, dan tidak tercerabut } \\
\text { dari akar budaya bangsa } \\
\text { namun } \\
\text { tetap bisa menjadi aktor } \\
\text { di zamannya. }\end{array}$ \\
\hline 6 & Iii & $\begin{array}{l}\text { Bahasa Arab ini diharapkan } \\
\text { mampu menjadi acuan cara } \\
\text { berfikir, bersikap dan bertindak }\end{array}$ & $\begin{array}{l}\text { Bahasa Arab ini } \\
\text { diharapkan mampu } \\
\text { menjadi acuan cara } \\
\text { berfikir, bersikap, dan } \\
\text { bertindak }\end{array}$ \\
\hline 7 & Iii & $\begin{array}{l}\text { Semoga Allah SWT memberikan } \\
\text { pahala yang tidak akan } \\
\text { terputus, dan semoga buku ini } \\
\text { benar-benar berkah-manfaat bagi } \\
\text { Agama, Nusa dan Bangsa. }\end{array}$ & $\begin{array}{l}\text { Semoga Allah SWT } \\
\text { memberikan pahala yang } \\
\text { tidak akan } \\
\text { terputus dan semoga } \\
\text { buku ini benar-benar } \\
\text { berkah-manfaat bagi } \\
\text { Agama, Nusa, dan } \\
\text { Bangsa. }\end{array}$ \\
\hline
\end{tabular}

\section{Aspek Penyajian}

\begin{tabular}{|c|c|c|}
\hline No. & Kesalahan & Keterangan \\
\hline 1 & $\begin{array}{l}\text { Ketidaksesuaian urutan materi di } \\
\text { buku ajar dengan Kurikulum } \\
\text { Bahasa Arab MI }\end{array}$ & 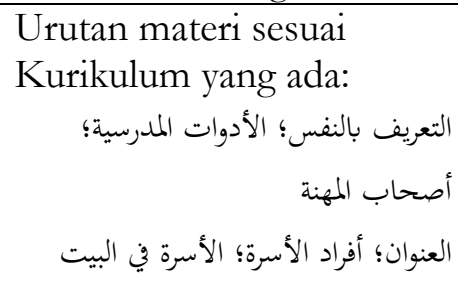 \\
\hline
\end{tabular}


Al Maqayis Jurnal Pendidikan Bahasa Arab dan Kebahasaaraban, 5 (2), 2018

\begin{tabular}{|c|c|c|}
\hline & & $\begin{array}{l}\text { Urutan materi sesuai di } \\
\text { buku ajar: } \\
\text { العنوان - المهنة - أملي - أفراد الأسرة - أحب الإندونيسيا }- \text { البيت }\end{array}$ \\
\hline 2 & $\begin{array}{l}\text { Terdapat materi yang dihilangkan } \\
\text { dan materi yang baru }\end{array}$ & $\begin{array}{l}\text { التعريف بالنفس؛ المي: dihilangkang } \\
\text { الأدوات المدرسية } \\
\text { diganti dengan materi tentang أحب إندونيسيا }\end{array}$ \\
\hline
\end{tabular}

\section{Aspek Kegrafikaan}

\begin{tabular}{|c|l|l|c|}
\hline No. & Hal. & \multicolumn{1}{|c|}{ Kesalahan } & Keterangan \\
\hline 1 & 53 & $\begin{array}{l}\text { Warna background dan } \\
\text { tulisan kurang sesuai sehingga } \\
\text { bisa menimbulkan } \\
\text { ketidakjelasan tulisan. }\end{array}$ & \\
\hline
\end{tabular}

Aspek Isi. Dari hasil analisis pada bagian nilai dan norma kebangsaan, secara keseluruhan, isi buku siswa Bahasa Arab MI kelas IV ini, terhindar dari unsur ketidakpatutan. Materi yang disajikan dalam buku ini tidak mengandung unsur pornografi, ekstrimisne dan radikalisme, kekerasan dan penistaan, SARA, bias gender, ujaran kebencian, serta penyimpangan dalam bentuk lainnya.

Pada bagian materi dan isi, buku ini masih terdapat kesalahan dalam hal baris sebuah kosakata seperti nama jalan yang seharusnya tetap karena merupakan isim alam jadi berubah karena terdapat huruf jar sebelumnya. Kemudian peletakkan materi yang dirasa salah sebab meletakkan pembelajaran mufradat bukan pada bagian awal setiap bab. Setiap bab juga tidak ada bagian khusus yang meletakkan terkait pengajaran qawaid, tetapi langsung dengan contoh penggunaannya. Lalu terdapat sedikit kesalahan dalam pemilihan gambar-gambar untuk beberapa mufradat pada buku seperti dari warna atau gambar yang hilang karena warna yang sama dengan background. Seperti yang kita ketahui, jika siswa MI sangat suka akan gambar-gambar dan itu bisa menarik perhatian mereka. Pada bagian awal juga terdapat ketidaksesuaian antara peta konsep, indikator pencapaian, dan KD terhadap Kurikulum Bahasa Arab MI sebagaimana tercantum pada Permenag no 912 tahun 2013.

Metode yang disampaikan pada buku saya rasa sangat monoton, terlihat seperti mengambil contoh pada bab sebelumnya. Selain itu dalam buku ini tidak didesain pembelajaran yang terlihat menyenangkan seperti lagu atau permainan bahasa agar menarik perhatian siswa dalam belajar. Karena siswa MI masih lebih suka jika terdapat unsur permainan. 


\section{Al Ma qayis Jurnal Pendidikan Bahasa Arab dan Kebahasaaraban, 5 (2), 2018 p-ISSN 2338-1337 e-ISSN 2615-3890}

Untuk latihan yang disajikan dirasa sudah cukup untuk jenjang kelas IV dan setiap latihan juga terdapat perintah yang terdiri dari bahasa Arab dan Indonesia sehingga membantu siswa dalam memahami maksud.

Aspek Bahasa. Bahasa Arab yang digunakan terlihat cukup bisa dipahami oleh siswa dengan dibantu adanya kosakata juga glosarium di akhir buku yang berguna bagi siswa. Selain itu dalam hal penulisan masih terdapat kesalahan seperti penggunaan koma, salahnya menulis beberapa kata-kata, dan penggunaan kalimat yang kurang bagus untuk dibaca.

Aspek Penyajian. Pada bagian ini, buku sudah menyajikan terkait KI,KD, Indikator, Peta Konsep, Glosarium yang berupa kamus terkait mufradat, dan juga transliterasi. Dalam penyajian materi pada buku ini masih tidak sesuai urutan dengan apa yang tertera di kurikulum bahasa Arab baik Permenag no 912 tahun 2013 ataupun KMA 165 tahun 2014. Penyajian materi yang seharusnya berada di semester genap, di buku ini diletakkan pada semester ganjil. Terdapat 2 materi yang seharusnya ada jika dilihat dari kurikulum bahasa Arab MI, tapi di buku ini dihilangkan dan diganti dengan materi yang lain. Cara penyajian materi tiap bab pun sama antara 1 bab dengan bab lainnya. Dalam penyajiaannya sudah melibatkan siswa, tetapi dirasa kurang bisa merangsang ketertarikan siswa terkait pembelajaran. Jika berdasakan pendapat Azkia Muharom terkait kecenderungan materi ajar bahasa Arab MI, dapat diketahui jika materi tentang seharusnya tidak perlu ditambahkan ke dalam buku ajar.

Aspek Kegrafikaan. Berkaitan dengan desain grafik pada buku, secara umum terlihat sangat bagus dan menarik. Dengan paduan warna mulai dari cover awal buku dan pada setiap materi ditampilkan gambar-gambar berwarna yang menarik. Selain itu keteraturan isi dari sisi letak, spasi antar paragraf, dan penempatan judul terlihat cukup bagus. Namun jika terlihat lagi, ada beberapa tampilan pada buku yang terlihat sangat padat. Tetapi, juga terdapat bagian warna pada buku yang kurang kontras dengan tulisan. Walaupun masih bisa terlihat, tetapi masih kurang jelas yaitu pada bagian kosakata yang terdapat di bab 4.

\section{Penutup}

Setelah dilakukan analisis terkait beberapa aspek terhadap Buku Bahasa Arab MI kelas 4, dapat disimpulkan bahwa buku ini masih memiliki beberapa aspek yang kurang sesuai baik dari segi isi materi, penyajian materi, dan bahasa. Terutama kurangnya kesesuaian antara susunan KD yang terdapat pada buku ajar dan kurikulum bahasa Arab. Tetapi pada aspek kegrafikaan dapat dijadikan sebagai salah satu aspek yang terlihat bagus walaupun masih terdapat sedikit kesalahan. Dan sebaiknya buku ini perlu adanya kegiatan telaah lagi lebih lanjut guna menghindari kesalahan-kesalahan terkait beberapa aspek yang telah disebutkan. 
Al Maqayis Jurnal Pendidikan Bahasa Arab dan Kebahasaaraban, 5 (2), 2018

p- ISSB 23381337 e-ISSN 2615-3890

\section{Daftar Pustaka}

Afifa Wijdan Azhari. "ANALISIS BUKU AJAR BAHASA ARAB KELAS VI MADRASAH IBTIDAIAH TERBITAN KARYA TOHA PUTRA.” Alsuniyat: Jurnal Penelitian Bahasa, Sastra, dan Budaya Arab Vol. 1, no. 2 (Oktober 2018).

Albantani, Azkia Muharom. "Pembelajaran Bahasa Arab Di Madrasah Ibtidaiyah: Sebuah Ide Terobosan." Attadib Journal Of Elementary Education Vol. 3, no. 2 (Desember 2018).

Al-Gali, A. and Abdul Hamid Abdullah. Menyusun Buku Ajaran Bahasa Arab. Padang: Akademia, 2012.

Faoziyah, Laila and Nailul Izzah. "Analysis of Arabic Language Textbooks for Madrasah Aliyah Class XI Based on the 2013 Curriculum | Analisis Buku Ajar Bahasa Arab Madrasah Aliyah Kelas XI Berdasarkan Kurikulum 2013." Mantiqu Tayr: Journal of Arabic Language Vol. 1, no. 2 (July 2021).

Hadi, Nurul. "ANALISIS CONTENT BUKU AJAR BAHASA ARAB (PENDEKATAN SAINTIFIK KURIKULUM 2013) KELAS I MADRASAH IBTIDAIYAH TERBITAN KEMENTRIAN AGAMA REPUBLIK INDONESIA 2014." IJAZ ARABI Journal of Arabic Learning Vol. 1, no. 1 (April 2018).

Mabrurrosi. "Analisis Buku Ajar Bahasa Arab Karya Dr. D. Hidayat." Al-Irfan Vol. 3, no. 2 (2020).

Majid, Abdul. Pendekatan Ilmiah Dalam Implemenasi Kurikulum 2013. Bandung: PT Remaja Rosdakarya, 2014.

Martatik. "ANALISIS BUKU BAHASA ARAB PENDEKATAN SAINTIFIK KURIKULUM 2013 MADRASAH IBTIDAIYAH KELAS I.” Andagogi Jurnal Diklat Teknis Vol. 6, no. 1 (June 2018).

Musclich, M. Text Book Writing: Dasar-Dasar Pemahaman, Penulisan, Dan Pemakaian Buku Teks. Sleman: AR-RUZZ Media, 2010.

Peraturan Mentri Pendidikan dan Kebudayaan. Nomor 8 Tabun 2016 Tentang Buku Yang Digunakan Oleh Satuan Pendidikan, 2015.

Permenag RI. Nomor 912 Tabun 2013 Tentang KURIKULUM MADRASAH 2013 MATA PELAJARAN PENDIDIKAN AGAMA ISLAM DAN BAHASA $A \mathrm{R} A B, 2013$. 
Al Maqayis Jurnal Pendidikan Bahasa Arab dan Kebahasaaraban, 5 (2), 2018 p-ISSN 2338-1337 e-ISSN 2615-3890

Ramah, Sutri and Miftahur Rohman. "Analisis Buku Ajar Bahasa Arab Madrasah Aliyah Kurikulum 2013.” Arabiyatuna: Jurnal Babasa Arab Vol. 2, no. 2 (2018).

Rosyad, Muh. Sabilar. "Analisis Buku Ajar Bahasa Arab Siswa Kelas VIII MTs/SMP Islam Dalam Perspektif Gender.” JALIE: Journal of Applied Linguistics and Islamic Education Vol. 2, no. 2 (September 2018).

Sitepu. Penulisan Buku Teks Pelajaran. Bandung: PT Remaja Rosdakarya, 2015.

Susanti, Rini Dwi. "STUDI ANALISIS MATERI AJAR "BUKU TEKS PELAJARAN" PADA MATA PELAJARAN BAHASA ARAB DI KELAS TINGGI MADRASAH IBTIDAIYAH.”'Arabia Vol. 5, no. 2 (July 2013).

Syaifullah, Muhammad and Nailul Izzah. "Kajian Teoritis Pengembangan Bahan Ajar Bahasa Arab." Arabiyatuna: Jurnal Bahasa Arab Vol. 3, no. 1 (2019). 